\title{
Pengintegrasian Nilai Pendidikan Karakter dalam Pembelajaran Bahasa Arab di Pusat Pengembangan Bahasa UIN Sunan Kalijaga Yogyakarta
}

\author{
Agung Setiyawan \\ Universitas Islam Negeri Sunan Kalijaga Yogyakarta \\ Email: agungsetiyawan871@gmail.com
}

\begin{abstract}
This study aims to determine the values of character education integrated into the learning Arabic Language Development Center UIN Sunan Kalijaga Yogyakarta and how to integrate and any problems faced by professors when integrating the value of the character education. This research is a field. Results showed the values of character education has been integrated include: religious, honest, tolerance, discipline, hard work, independent, democracy, curiosity, national spirit, recognize excellence, communicative, love reading, environmental care, and responsibility. How lecturer integrate include: adjust the lecture material, insert the value of a character. As for the difficulty in integrating include: the difficulty of adjusting the educational value of the existing character of the material.
\end{abstract}

Keywords: integration, characters education value, Arabic language learning.

\begin{abstract}
Abstrak
Penelitian ini bertujuan untuk mengetahui nilai-nilai pendidikan karakter yang terintegrasi ke dalam pembelajaran bahasa Arab di Pembangunan Pusat Bahasa UIN Sunan Kalijaga Yogyakarta dan bagaimana mengintegrasikan dan masalah yang dihadapi oleh para profesor ketika mengintegrasikan nilai pendidikan karakter. Penelitian ini merupakan lapangan. Hasil penelitian menunjukkan nilai-nilai pendidikan karakter telah terintegrasi meliputi: agama, jujur, toleransi, disiplin, kerja keras, mandiri, demokrasi, rasa ingin tahu, semangat kebangsaan, mengakui keunggulan, komunikatif, suka membaca, peduli lingkungan, dan tanggung jawab. Bagaimana dosen mengintegrasikan meliputi: menyesuaikan materi perkuliahan, masukkan nilai karakter. Adapun kesulitan dalam mengintegrasikan meliputi: kesulitan menyesuaikan nilai pendidikan karakter dengan material yang ada.
\end{abstract}

Kata kunci: integrasi, nilai karakter pendidikan, Pembelajaran Bahasa Arab. 


\section{Pendahuluan}

Era globalisasi telah membawa dampak luas di belahan bumi mana pun, tak terkecuali di negeri Indonesia. Dampak globalisasi diibaratkan seperti pisau bermata dua, positif dan negatif memiliki konsekuensi yang seimbang. Kompetisi, integrasi, dan kerjasama adalah dampak positif globalisasi. Sedangkan dampak negatif antara lain lahirnya generasi instan, dekadensi moral, konsumerisme, bahkan permisifisme. ${ }^{1}$ Selain itu dampak negatif lainnya adalah muncul tindakan kekerasan, penyalahgunaan obat-obat terlarang, seks bebas, dan kriminalitas. Semua hal negatif tersebut berujung pada hilangnya karakter bangsa. ${ }^{2}$

Masyarakat dewasa ini, khususnya remaja, memiliki kebiasaan mengikuti perkembangan gaya hidup yang sedang tren, mulai dari cara berpakaian, gaya berbicara, pergaulan yang selalu mengikuti perkembangan ilmu pengetahuan dan teknologi, serta budaya luar yang sedang populer. Hal ini berdampak pada menurunnya minat generasi muda pada hal-hal yang positif dan meningkatnya kenakalan remaja, yang antara lain terwujud dalam bentuk pergaulan bebas, penggunaan obat terlarang, minuman keras, dan perjudian. ${ }^{3}$

Menyikapi fenomena di atas, dunia pendidikan ${ }^{4}$ harus memberi peran penting dalam menangkal dekadensi moral bangsa, dalam

${ }^{1}$ Jamal Ma'mur Asmani, Buku Panduan Internalisasi Pendidikan Karakter di Sekolah, (Yogyakarta: Diva Press, 2012), hlm. 7. Gaya hidup hedonistik dan permisif di era globalisasi sebagaimana banyak ditayangkan dalam telenovela dan sinetron pada berbagai saluran televisi Indonesia, hanya mempercepat disorientasi dan dislokasi keluarga dan rumah tangga. Akibatnya banyak anak tidak memiliki kebajikan dan inner beauty dalam karakternya, namun mengalami kepribadian terbelah (split personality). Lihat Azyumardi Azra, Paradigma Baru Pendidikan Nasional; Rekonstruksi dan Demokratisasi, (Jakarta: Kompas, 2002), hlm. 172-173.

${ }^{2}$ Barnawi \& M. Arifin, Strategi dan Kebijakan Pembelajaran Pendidikan Karakter, (Yogyakarta: Ar-Ruzz Media, 2013), hlm. 5.

${ }^{3}$ Berdasarkan data dari Komisi Perlindungan Anak Indonesia (KPAI, 2003) menyatakan sebanyak 32\% remaja usia 14 hingga 18 tahun di kota-kota besar Indonesia (Jakarta, Surabaya, dan Bandung) pernah berhubungan seks. Kasus lain berdasarkan data Badan Narkotika Nasional (BNN) hingga tahun 2008 pengguna narkoba di Indonesia mencapai 3,2 juta orang. Dari jumlah ini $32 \%$ adalah pelajar dan mahasiswa. Baca Agus Wibowo, Pendidikan Karakter, Strategi Membangun Karakter Bangsa Berperadaban, (Yogyakarta: Pustaka Pelajar, 2012), hlm. 8-10.

${ }^{4}$ Dalam bahasa Indonesia, kata pendidikan berasal dari kata didik (memelihara dan memberi latihan, ajaran, bimbingan mengenai akhlak dan 
upaya menyiapkan generasi muda masa depan yang lebih baik. ${ }^{5}$ Dalam sistem pendidikan nasional, Undang-Undang telah mengamanatkan tujuan pendidikan diarahkan agar peserta didik menjadi manusia beriman dan bertakwa, memiliki akhlak mulia, sehat lahir maupun batin, berilmu, memiliki kecakapan dan kreatifitas, memiliki kemandirian, menjadi warga negara yang demokratis dan memiliki sikap bertanggung jawab. ${ }^{6}$

Para cendikiawan telah menawarkan berbagai wacana baru tentang model dan muatan pendidikan. Pendidikan semakin urgen untuk diperhatikan, terutama pendidikan karakter bangsa. Pendidikan karakter merupakan salah satu hal penting bagi semua bangsa, tidak terkecuali Indonesia. ${ }^{7}$ Penanaman nilai pendidikan karakter sudah seharusnya diberikan kepada seluruh rakyat Indonesia, terutama anak-anak dan para pemuda yang nantinya menjadi generasi penerus bangsa ini. Kajian mengenai pendidikan karakter telah

kecerdasan pikiran) yang mendapat awalan pen- dan akhiran -an. Kata tersebut sebagaimana dijelaskan dalam Kamus Besar Bahasa Indonesia adalah perbuatan, (hal, cara dan sebagainya) mendidik. Lihat Suharso dan Ana Retnoningsih, Kamus Besar Bahasa Indonesia edisi lux, (Semarang: Widya Karya, 2011), hlm. 122. Dalam pengertian kebahasaan, kata pendidikan sering diterjemahkan ke dalam bahasa Arab oleh para ahli pendidikan Islam dengan kata tarbiyah. Sebuah buku karangan Muhammad Athiyah al-Abrasyi yang berjudul at-Tarbiyah al-Islamiyah diterjemah ke dalam bahasa Indonesia oleh Prof. H. Bustami A. Ghani (pakar di bidang bahasa Arab dari Indonesia) dan Johar Bahri menjadi Dasar-dasar Pokok Pendidikan Islam. Demikian pula buku yang berjudul Min al-Ushul al-Tarbawiyah fi al-Islam karangan Abdul Fattah Jalal diterjemahkan ke dalam bahasa Indonesia menjadi Dasar-dasar Pemikian Islam. Lihat Abudin Nata, Filsafat Pendidikan Islam, (Jakarta: Gaya Media Patama, 2005), hlm. 5.

${ }^{5}$ Lebih lanjut Azyumardi Azra menjelaskan bahwa kondisi tersebut menggambarkan tentang pentingnya gagasan tentang diskursus pendidikan budi pekerti atau karakter untuk direkonseptualisasi kembali. Karena terlihat pendidikan nasional pada setiap jenjang, khususnya jenjang menengah dan tinggi "telah gagal" dalam membentuk peserta didik yang memiliki akhlak, moral, dan budi pekerti yang baik. Baca Azyumardi Azra, Paradigma Baru ..., hlm. 178.

${ }^{6}$ Lihat Undang-Undang Republik Indonesia Nomor 20 Tahun 2003 Tentang Sistem Pendidikan Nasional.

${ }^{7}$ Presiden pertama Republik Indonesia, Ir. Soekarno, bahkan menegaskan: "Bangsa ini harus dibangun dengan mendahulukan pembangunan karakter (character building) karena character building inilah yang akan menjadikan bangsa Indonesia menjadi bangsa yang besar, maju, jaya serta bermartabat". Lihat Muchlas Samani dan Hariyanto, Konsep Dan Model Pendidikan Karakter, (Bandung: PT Remaja Rosdakarya, 2013), hlm. 1-2. 
banyak dilakukan dan masih hangat untuk tetap diperbincangkan sampai sekarang. Bahkan hal ini perlu sekali dikembangkan agar pendidikan karakter tidak hanya sekedar teori yang hampa implementasi. Akan tetapi pendidikan karakter haruslah dapat diwujudkan dan diterapkan dalam setiap perilaku kehidupan sehari-hari.

Penerapan konsep pendidikan karakter dapat dilakukan salah satu caranya dengan diintegrasikan melalui pembelajaran, yakni dengan memasukkan nilai-nilai karakter dalam setiap mata pelajaran. Suatu pembelajaran tidak hanya berfungsi pada aspek kognitif saja, akan tetapi juga pada aspek afektif serta psikomotorik. Inilah hakikat dari suatu pembelajaran. Melalui pembelajaran seseorang dapat mengetahui sesuatu yang belum pernah ia ketahui. Pengintegrasian nilai-nilai karakter ini bukan hanya terjadi pada mata pelajaran pendidikan agama saja, melainkan semua jenis mata pelajaran, termasuk di dalamnya bahasa Arab. ${ }^{8}$

Bahasa Arab merupakan salah satu materi pokok yang biasa diajarkan di setiap lembaga pendidikan Islam. Pembelajaran bahasa Arab idealnya memungkinkan para peserta didik untuk mampu menguasai empat keterampilan berbahasa (maharat al-istima', alkalam, al-qira'ah, dan al-kitabah) secara fungsional dan proporsional. Hal ini dikarenakan bahasa Arab bukan hanya sekedar berfungsi reseptif, yaitu sebagai media untuk memahami (al-fahm) apa yang dapat didengar, berita, teks, bacaan, dan wacana, melainkan juga berfungsi produktif atau ekspresif, yaitu untuk memahamkan (al-ifham) orang lain melalui komunikasi lisan dan tulisan. ${ }^{9}$

Universitas Islam Negeri Sunan Kalijaga Yogyakarta yang selama ini memainkan peran aktifnya dalam kehidupan sosial-

\footnotetext{
${ }^{8}$ Pengintegrasian nilai-nilai karakter dalam pembelajaran bahasa Arab tidak mudah dilakukan. Pengajar bahasa Arab harus pandai menyesuaikan materi pembelajaran yang diajarkan dengan nilai-nilai karakter yang dapat diintegrasikan dalam pembelajaran tersebut. Karena itu, tidak semua pengajar bahasa Arab dapat mengintegrasikan nilai karakter dalam pembelajaran bahasa Arab dengan baik. Dengan memahami konsep dasar pembelajaran bahasa Arab dan pendidikan karakter serta paham cara mengintegrasikannya, maka proses pengintegrasian nilai-nilai karakter kepada peserta didik dapat dilaksanakan dengan baik pula. Lihat Thoyib Panji Pambudi, Pengintegrasian Nilai Karakter Dalam Pembelajaran Bahasa Arab di MTs Negeri Sayegan Tahun Ajaran 2013/2014, (Skripsi, Fakultas Ilmu Tarbiyah dan Keguruan, UIN Sunan Kalijaga, Yogyakarta, 2014), hlm. 4.

${ }^{9}$ Lihat Muhbib Abdul Wahab, Epistimologi Dan Metodologi Pembelajaran Bahasa Arab, (Jakarta: Lembaga Penelitian Universitas Islam Negeri Syarif Hidayatullah Jakarta, 2008), hlm. 17-18.
} 
religius masyarakat, dihadapkan pada tanggung jawab penguatan kompetensi bahasa Arab bagi seluruh mahasiswanya. Penguatan kompetensi bahasa Arab diposisikan sangat penting dalam rangka memahami, mendalami dan menguasai sumber ajaran Islam, yang kemudian diteruskan dan ditransformasikan kepada masyarakat. Di sisi lain penguatan kompetensi bahasa Arab tidak hanya sebagai respon terhadap realitas sosial-religius masyarakat, tetapi terkait juga dengan konteks penanaman nilai moral kepada peserta didik dalam hal ini mahasiswa agar menjadi lulusan yang religius, berilmu dan beretika.

Pusat Pengembangan Bahasa UIN Sunan Kalijaga adalah suatu lembaga yang memiliki peran penting dalam pengembangan dan peningkatan keterampilan berbahasa asing terutamanya bagi mahasiswa UIN Sunan Kalijaga. Pembelajaran yang dilaksanakan di Pusat Pengembangan Bahasa UIN Sunan Kalijaga memiliki keistimewaan dengan dirancangnya sistem pembelajaran yang berbasis pendidikan karakter. Pendidikan karakter diintegrasikan melalui berbagai hal yang terkait dengan pembelajaran di antaranya tertuang dalam materi pembelajaran serta teraplikasi pula melalui metode dan strategi yang digunakan oleh para dosen dalam proses pembelajaran.

\section{Konsep Pendidikan Karakter}

Secara harfiah, istilah karakter berasal dari bahasa Inggris 'character' yang berarti watak, karakter, atau sifat. ${ }^{10}$ Dalam Kamus Bahasa Indonesia, watak diartikan sebagai sifat batin manusia yang mempengaruhi segenap pikiran dan perbuatannya, atau berarti tabiat, dan budi pekerti. ${ }^{11}$ Karakter adalah tabiat, sifat-sifat kejiwaan, akhlak, atau budi pekerti yang membedakan seseorang dengan yang lain. ${ }^{12}$ Dengan demikian, istilah pendidikan karakter

${ }^{10}$ John M. Echols dan Hasan Shadily, Kamus Inggris Indonesia, (Cet. VII; Jakarta: Gramedia, 1979), hlm. 107.

${ }^{11}$ Tim Penyusun, Kamus Bahasa Indonesia, (Cet. XVI; Jakarta: Pusat Bahasa, 2008), hlm. 1811.

12 Wynne dalam E. Mulyasa mengemukakan bahwa karakter berasal dari bahasa Yunani yang berarti "to mark" (menandai) dan memfokuskan pada bagaimana menerapkan nilai-nilai kebaikan dalam tindakan nyata atau perilaku sehari-hari. Oleh sebab itu, orang yang berperilaku tidak jujur, curang, kejam, dan rakus dikatakan sebagai orang yang berkarakter jelek. Sebaliknya, yang berkelakuan baik, jujur, dan suka menolong dikatakan sebagai orang 
merupakan upaya mempengaruhi segenap pikiran dengan sifat-sifat batin tertentu, sehingga dapat membentuk watak, budi pekerti, dan mempunyai kepribadian. ${ }^{13}$

Nilai-nilai yang ada dalam pendidikan karakter bersumber dari agama, pancasila, budaya, dan tujuan pendidikan nasional berjumlah 18, yaitu: (1) religius, (2) jujur, (3) toleransi, (4) disiplin, (5) kerja keras, (6) kreatif, (7) mandiri, (8) demokratis, (9) rasa Ingin tahu, (10) semangat kebangsaan, (11) cinta tanah air, (12) menghargai prestasi, (13) bersahabat/ komunikatif, (14) cinta damai, (15) gemar membaca, (16) peduli lingkungan, (17) peduli sosial, dan (18) tanggung jawab. ${ }^{14}$

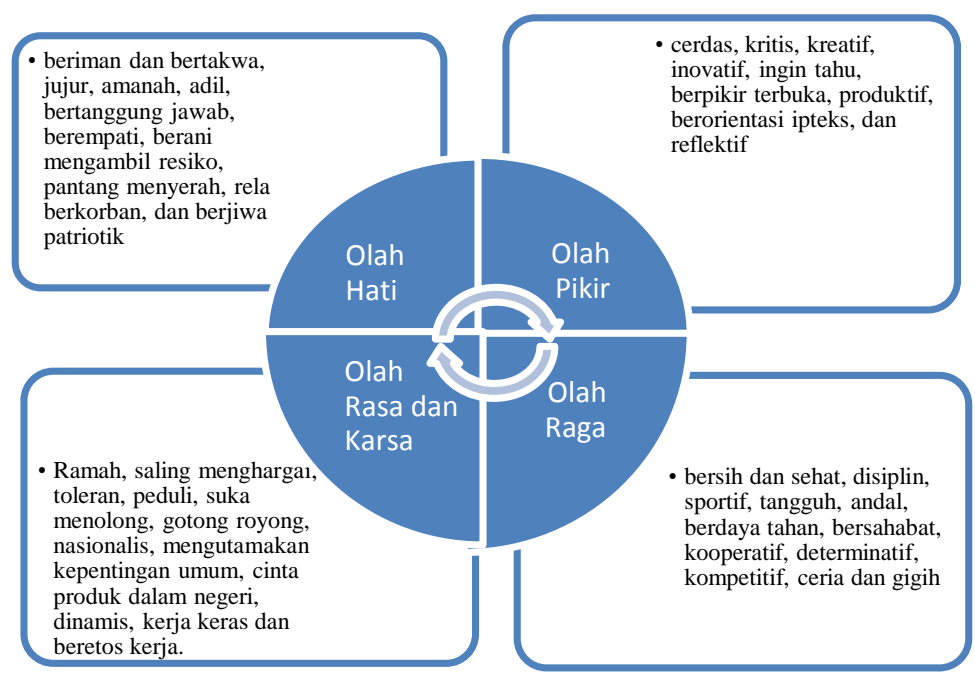

Gambar 1: Keterpaduan Olah Hati, Olah Pikir, Olah Raga, Olah Rasa Dan Karsa ${ }^{15}$

yang memiliki karakter baik atau mulia. Lihat Mulyasa, Manajemen Pendidikan Karakter, (Jakarta: Bumi Aksara. 2011), hlm. 3.

${ }^{13}$ Pendidikan karakter didefinisikan sebagai pendidikan yang mengembangkan karakter yang mulia (good character) dari peserta didik dengan mempraktikkan dan mengajarkan nilai-nilai moral dan pengambilan keputusan yang beradab dalam hubungan dengan sesama manusia maupun dalam hubungannya dengan Tuhannya. Muchlas Samani dan Hariyanto, Konsep Dan Model Pendidikan Karakter, (Bandung: PT Remaja Rosdakarya, 2013), hlm. 44.

${ }^{14}$ Muchlas Samani dan Hariyanto, Konsep ..., hlm. 52.

${ }^{15}$ Muchlas Samani dan Hariyanto, Konsep ..., hlm. 24-15. 
Secara psikologis, karakter individu dimaknai sebagai hasil keterpaduan empat bagian, yakni olah hati, olah pikir, olah raga, olah rasa dan karsa. Olah hati berkenaan dengan perasaan, sikap, dan keyakinan/keimanan. Olah pikir berkenaan dengan proses nalar guna mencari dan menggunakan pengetahuan secara kritis, kreatif dan inovatif. Olah raga berkenaan dengan proses persepsi, kesiapan, peniruan, manipulasi dan penciptaan aktivitas barudi serta sportivitas. Sedangkan olah rasa dan karsa berkenaan dengan kemauan, motivasi, dan kreaktivitas yang tercermin dalam kepedulian, citra, dan penciptaan kebaruan. Keterpaduan itu secara ringkas ditunjukkan dalam gambar di atas.

Untuk mewujudkan nilai-nilai karakter dalam kepribadian perlu ditekankan tiga komponen (components of good character) penting yakni; moral knowing (pengetahuan tentang moral), moral feeling (perasaan tentang moral), dan moral action (tindakan moral). ${ }^{16}$ Ketiga komponen ini dapat memberikan pemahaman bahwa karakter yang baik harus didukung oleh pengetahuan tentang kebaikan, keinginan untuk berbuat baik, dan kemampuan melakukan perbuatan baik. Dengan kata lain, indikator manusia yang memiliki kualitas pribadi yang baik adalah mereka yang mengetahui kebaikan, memiliki keinginan untuk berbuat baik, dan nyata berperilaku baik, yang secara koheren memancar sebagai hasil dari 5 (lima) olah, yaitu: olah pikir, olah hati, olah raga, olah rasa, dan olah karsa. Dan hal ini sesuai dengan grand design yang dikembangkan oleh kemendiknas tahun 2010 dalam upaya pembentukan karakter dalam diri tiap individu. ${ }^{17}$

Untuk itu, sungguh tepat ungkapan Nasih A. Ulwan ketika mendefenisikan "Pendidikan Karakter" sebagai suatu usaha yang sengaja dilakukan agar obyek didik memperoleh sekumpulan

${ }^{16}$ Moral knowing adalah adanya kemampuan seseorang membedakan nila-nilai akhlak mulia dan akhlak tercela serta nilai-nilai universal. Sedangkan moral feeling dimaksudkan untuk menumbuhkan rasa cinta dan rasa butuh terhadap nilai-nilai akhlak mulia, sehingga tumbuh kesadaran dan keinginan serta kebutuhan untuk menilai dirinya sendiri, Adapun moral action adalah menampakkan pembiasaan perilaku-perilaku yang baik dan terpuji pada diri seseorang dalam kehidupan sehari-hari. Lihat Abdul Majid dan Dian Andayani, Pendidikan Karakter Perspektif Islam, (Cet. II: Bandung: Remaja Rosdakaya, 2012), hlm. 112.

${ }^{17}$ Kementerian Pendidikan Nasional Dirjen Pendidikan Dasar Direktorat Pembinaan Sekolah Menengah Pertama, Panduan Pendidikan Karakter di Sekolah Menengah Pertama, Jakarta: Diknas, 2011, h. 16. 
prinsip-prinsip budi pekerti, karakter yang mulia dan keutamaankeutamaan perilaku dan perasaan, lalu terbiasa dengannya sejak dini sampai ia dewasa dan bergumul dengan kehidupan nyata. ${ }^{18}$

Adapun tujuan dari pendidikan karakter secara umum ialah meningkatkan, mengembangkan, melestarikan, serta memperaktekan atau menerapkan nilai-nilai atau karakter positif dalam kehidupan berkeluarga, bermasyarakat, berbangsa dan bernegara. Sedangkan tujuan pendidikan karakter secara khusus adalah meningkatkan kesadaran dan pengetahuan terhadap nilai-nilai kemanusiaan; nilainilai budaya, sosial, dan agama; menanamkan nilai-nilai kejujuran, loyalitas, dan integritas; meningkatkan kemampuan mengendalikan emosi, dan bersikap terbuka; melatih kepekaan dan kepedulian terhadap lingkungan; meningkatkan rasa tanggungjawab dan kedisiplinan generasi muda; melatih kemampuan membedakan yang baik dan yang buruk. 19

\section{Gambaran Umum Desain Pembelajaran Bahasa Arab di Pusat Pengembangan Bahasa UIN Sunan Kalijaga Yogyakarta}

Pusat Pengembangan Bahasa UIN Sunan Kalijaga mempunyai tiga fungsi utama. Pertama, melaksanakan pelatihan bahasa asing

${ }^{18}$ Nasih A. Ulwan, Tarbiyatul Awlaad fi al-Islaam, Cet.XXI , Jilid I, (Jeddah: Daarussalaam, 1992), hlm. 177.

${ }^{19}$ Kementerian Pendidikan Nasional Dirjen Pendidikan Dasar Direktorat Pembinaan Sekolah Menengah Pertama, Panduan Pendidikan Karakter..., hlm. 7. Sedangkan tujuan Pendidikan karakter secara terperinci terbagi menjadi lima tujuan. Pertama, mengembangkan potensi kalbu/nurani/afektif peserta didik sebagai manusia dan warga negara yang memiliki karakter bangsa. Kedua, mengembangkan kebiasaan dan perilaku peserta didik yang terpuji dan sejalan dengan nilai-nilai universal dan tradisi budaya bangsa yang religius. Ketiga, menanamkan jiwa kepemimpinan dan tanggungjawab peserta didik sebagai penerus bangsa. Keempat, mengembangkan kemampuan peserta didik menjadi manusia yang mandiri, kreatif, dan berwawasan kebangsaan. Kelima, mengembangkan lingkungan kehidupan sekolah sebagai lingkungan belajar yang aman, jujur, penuh kreativitas dan persahabatan, dan dengan rasa kebangsaan yang tinggi dan penuh kekuatan. Lihat Dharma Kesuma, Cepi Triatna dan Johar Permana, Pendidikan Karakter Kajian Teodan Praktik Di Sekolah, (Bandung: PT Remaja Rosdakarya, 2012), hlm. 6-10. Selain itu disebutkan pula bahwa tujuan pendidikan karakter adalah merubah manusia menjadi lebih baik dalam pengetahuan, sikap dan keterampilan. Lihat Abdul Majid dan Dian Andayani, Pendidikan Karakter ..., hlm. 30. 
guna memudahkan para tenaga edukatif dan mahasiswa mempelajari buku-buku literature berbahasa asing. Kedua, membantu meningkatkan penguasaan bahasa asing guna mengikuti pendidikan lanjutan bagi tenaga edukatif dan mahasiswa ke luar negeri. Ketiga, membantu penguasaan bahasa asing bagi masyarakat yang membutuhkan.

Adapun desain pembelajaran di Pusat Pengembangan Bahasa UIN Sunan Kalijaga terdiri dari empat desain utama, yaitu: desain tujuan pembelajaran (learning objectives design), desain materi pembelajaran (content design), desain strategi pembelajaran (instructional strategies disign) dan desain evaluasi (evaluation design).

1. Desain Tujuan Pembelajaran Bahasa Arab di Pusat Pengembangan Bahasa UIN Sunan Kalijaga Yogyakarta

Program Pembelajaran Bahasa Arab di Pusat pengembangan Bahasa UIN Sunan Kalijaga ini diselenggarakan dengan tujuan sebagai berikut :

a. Meningkatkan kemampuan berbahasa Arab bagi mahasiswa.

b. Memfasilitasi pembelajaran bahasa Arab secara terpadu.

c. Menumbuhkembangkan budaya berbahasa asing.

d. Menjembatani untuk pencapaian sasaran mutu UIN Sunan Kalijaga

e. Membina dan mengembangkan kepribadian mahasiswa melalui media bahasa.

2. Desain materi pembelajaran bahasa arab di pusat pengembangan bahasa uin sunan kalijaga yogyakarta

Materi bahasa Arab yang diajarkan di Pusat Pengembangan bahasa diklasifikasikan menjadi tiga level yaitu mubtadi', mutawassit, dan mutaqaddim. Setiap modul mencakup empat kemahiran (maharah) atau keterampilan (skill) berbahasa yaitu, keterampilan mendengar (maharah al-istima'), keterampilan berbicara (maharah al-kalam), keterampilan membaca (maharah al-qira'ah), dan keterampilan menulis (maharah al-kitabah). Keempat aspek tersebut dihimpun mulai dari al-hiwar (percakapan), at-ta'birat (ungkapan), al-asalib wa al-Qawaid al-lughawiyyah (gaya bahasa dan tata bahasa), al-qira'ah (bacaan), al-mufrodat (kosakata), mahfudzah mukhtarah (katakata mutiara pilihan), dan at-tadribat (latihan).

Pada semua tingkatan, desain materi tersusun dari hal yang mudah dan sederhana menuju materi yang lebih sulit dan kompleks. 
Konten materi dalam modul tersebut dipaparkan perbab dan berisi sub bab yang memisahkan tema satu dengan yang lainnya. Selain itu, modul juga diberi gambar-gambar sehingga terkesan menarik dan tidak membosankan.

Untuk memfasilitasi proses belajar-mengajar di kelas, Pusat Pengembangan Bahasa UIN Sunan Kalijaga Yogyakarta menggunakan buku ajar yang berjudul الجامعة لتعليم اللغة العربية. Berikut judul materi yang diajarkan pada setiap tingkatan:

$$
\begin{aligned}
& \text { a. الكتاب الأول } \\
& \text { الباب الأوّل : التعارف البف } \\
& \text { الباب الثّاني : الأسرة } \\
& \text { الثّالث : البحث عن الفصل الباب } \\
& \text { الباب الرابع : الطعام والشراب } \\
& \text { الباب الخامس : الحياة اليومية } \\
& \text { الباب السادس : العمل لئل } \\
& \text { الباب الأول : الرحلة إلى الخارج } \\
& \text { الباب الثاني : السفر لطلب العلم } \\
& \text { الباب الثالث : التعليم في إندونيسيا }
\end{aligned}
$$

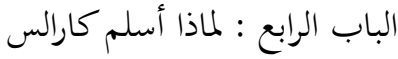

$$
\begin{aligned}
& \text { الباب الخامس : طالب جديد } \\
& \text { الباب السادس : أهمية المعهد في تكوين الجيل الناشئ } \\
& \text { c. الكتاب الثالث } \\
& \text { الباب الأول : العالم الإسلام } \\
& \text { الباب الثاني : الثقافة الإسلامية } \\
& \text { الباب الثالث : رحلة إلى لبنان } \\
& \text { الباب الرابع : الحياة في المدن الكبيرة } \\
& \text { الباب الخامس : البطالة }
\end{aligned}
$$


3. Desain metode pembelajaran bahasa arab di pusat pengembangan bahasa uin sunan kalijaga yogyakarta

Faktor yang sangat esensial dalam proses pembelajaran adalah metode pembelajaran yang digunakan. Beberapa metode pembelajaran yang digunakan dalam pembelajaran bahasa Arab di kelas Pusat Pengembangan Bahasa UIN Sunan Kalijaga Yogyakarta meliputi:

a. Metode Ceramah

Metode ini digunakan oleh dosen untuk menjelaskan materi, dengan materi buku yang berbahasa Arab tentunya banyak mufrodat atau istilah-istilah yang belum difahami maknanya.

b. Metode Demonstrasi

Metode demonstrasi adalah cara penyajian bahan pelajaran dengan memperagakan/mempertunjukkan cara atau situasi dalam pembelajaran sesuai dengan tujuan yang akan dicapai. Misalnya dengan mendemonstrasikan kalam di depan kelas, memperagakan hiwar (percakapan) yang ada di buku, berpidato dan sebagainya.

c. Metode Tanya Jawab

Metode tanya jawab merupakan metode dengan cara penyajian dalam bentuk pertanyaan yang harus dijawab oleh mahasiswa. Dosen selalu memberikan kesempatan kepada mahasiswa untuk menanyakan hal-hal yang berkaitan dengan dengan materi yang telah disampaikan atau sebaliknya.

d. Metode Diskusi

Metode diskusi merupakan upaya saling membantu antara dua orang atau lebih, antara individu dengan kelompok dalam menyelesaikan tugas. Misalnya, mahasiswa diminta untuk menganalisis teks dari segi nahwu dan sharaf-nya.

4. Desain evaluasi pembelajaran bahasa arab di pusat pengembangan bahasa uin sunan kalijaga yogyakarta

Adapun evaluasi pembelajaran bahasa Arab yang dilakukan di Pusat Pengembangan Bahasa adalah dalam bentuk partisipasi dan keaktifan mahasiswa (evaluasi proses), latihan-latihan dan tugas mandiri atau kelompok (evaluasi hasil). Adapun komposisi penilaian meliputi aspek kehadiran, keaktifan, tugas 
mandiri, ujian tengah semester dan ujian akhir semester yang secara detail digambarkan dalam tabel berikut ini: ${ }^{20}$

Tabel Aspek Penilaian Proses Pembelajaran

di Pusat Pengembangan Bahasa UIN Sunan Kalijaga Yogyakarta

\begin{tabular}{clc}
\hline No & Aspek yang dinilai & Persentase \\
\hline 1. & $\begin{array}{l}\text { Ujian Akhir } \\
\text { Semester (UAS) }\end{array}$ & $40 \%$ \\
\hline 2. & $\begin{array}{l}\text { Ujian Tengah } \\
\text { Semester (UTS) }\end{array}$ & $20 \%$ \\
\hline 3. & Tugas mandiri & $20 \%$ \\
\hline 4. & $\begin{array}{l}\text { Keaktifan dan } \\
\text { partisipasi } \\
\text { mahasiswa }\end{array}$ & $15 \%$ \\
\hline 5. & Sikap & $5 \%$ \\
\hline & Total & $\mathbf{1 0 0 \%}$
\end{tabular}

\section{Pembelajaran Nilai-nilai Pendidikan Karakter di Pusat Pengembangan Bahasa UIN Sunan Kalijaga Yogyakarta}

Hasil penelitian menunjukkan adanya pengintegrasian nilai-nilai karakter dalam materi pembelajaran yang terdapat dalam modul bahasa Arab. Nilai-nilai pendidikan karakter yang diajarkan yaitu:

1. Religius

Nilai pendidikan karakter ini terkandung dalam beberapa materi, diantaranya:

a. Ucapan salam ketika bertemu dengan orang lain

b. Ucapan tahmid sebagai bentuk syukur atas nikmat kesehatan yang telah Allah berikan

c. Teks mengenal keluarga Rasulullah SAW

d. Kata mutiara "من صبر ظفر"

2. Disiplin

Nilai pendidikan karakter ini terkandung dalam beberapa materi, diantaranya:

a. Kata mutiara “"من سار على الارب وصل".

${ }^{20}$ Hasil wawancara bersama koordinator program pembelajaran bahasa Arab, Ustadz Herman Ady, M.Si. 15 Juni 2015 di Kantor Pusat Pengembangan Bahasa (P2B) UIN Sunan Kalijaga Yogyakarta. 
3. Jujur
b. Teks qiraah “بومية عمر".

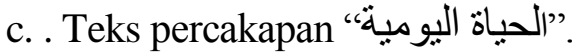

Nilai pendidikan karakter ini terkandung dalam beberapa materi, diantaranya:
a. Kata mutiara "من قلّ صدقه قلّ صديقه"
b. Cerpen "qishah su'al as-sa'b".
c. Kata mutiara "جالس أهل الصدق و الوفاء".

4. Mandiri

Nilai pendidikan karakter ini terkandung dalam beberapa materi, diantaranya:

a. Teks percakapan “الحياة اليومية”.

b. Kata mutiara

$$
\begin{aligned}
& \text { (أنفق على قدر ماستطعت و لا * تسرف و عش عيش مقتصد) } \\
& \text { (من كان فيما استفاد مقتصدا * لم تقتقرّ بعدها إلى أحد) }
\end{aligned}
$$

c. Teks qiraah "يومية عمر احهر".

5. Toleransi

Nilai pendidikan karakter ini terkandung dalam beberapa materi, diantaranya:

a. Kata mutiara "كل شيئ إذا كثر رخص إلاّ الأدب". b. Teks percakapan: "limadz aslama charles?". d. Teks percakapan "thalib jadid".

c. Cerpen "السائل الهرم".

6. Kerja Keras

Nilai pendidikan karakter ini terkandung dalam beberapa materi, diantaranya:

a. Kata mutiara "من جدّ وجد".

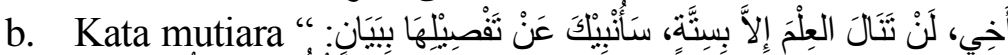

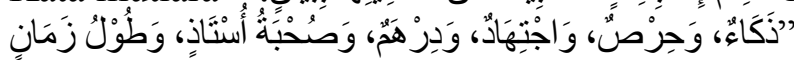

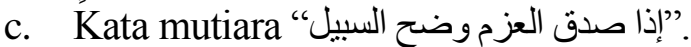

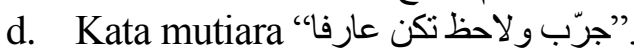

e. Teks qiraah "دور المنظمات الإسلامية في تحرير إندونيسيا" لونيا".

7. Rasa Ingin Tahu

Nilai pendidikan karakter ini terkandung dalam beberapa materi, diantaranya:

a. Teks percakapan: "limadz aslama charles?".

b. Cerpen "الرجل المجادل"

c. Kata mutiara

$$
\text { (شكوت إلى وكيع سوء حفظي * فأرشد ني إلى ترك المعاصي) }
$$




$$
\text { (فأخبرني بأ، العلم نور * ونور اله لا يهذى لعاصي) }
$$

d. Cerpen "qishah su'al as-sa'b".

8. Menghargai Prestasi

Nilai pendidikan karakter ini terkandung dalam beberapa materi, diantaranya:

a. Teks qiraah "البسانترين”.

b. Teks percakapan “طالب جديد".

9. Demokrasi

Nilai pendidikan karakter ini terkandung dalam beberapa materi, diantaranya:
a. Cerpen "بائع السمك".

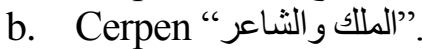
c. Teks hiwar “التعليم في إندونيسياع".

10. Komunikatif

Nilai pendidikan karakter ini terkandung dalam beberapa materi, diantaranya:
a. Teks tercakapan tentang “"التعارف".
b. Cerpen "الملك و الثاعر".

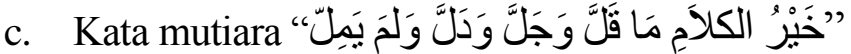

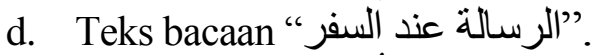

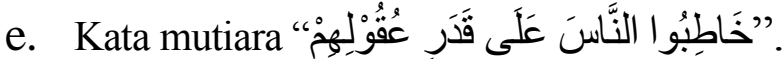

11. Semangat Kebangsaan

Nilai pendidikan karakter ini terkandung dalam beberapa materi, diantaranya:

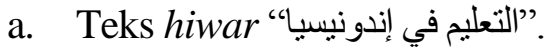

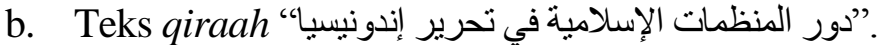
c. Teks qiraah “الديانات في إندونيسيا" 'إنديسيا".

12. Gemar Membaca

Nilai pendidikan karakter ini terkandung dalam beberapa materi, diantaranya:
a. Teks percakapan: "limadz aslama charles?".
b. Cerpen "qishah su'al as-sa'b".

13. Peduli Lingkungan

Nilai pendidikan karakter ini terkandung dalam beberapa materi, diantaranya:
a. Teks hiwar “التعليم في إندونيسيا"
b. Qiraah "الحياة في المدن"

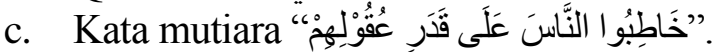




\section{Tanggung Jawab}

Nilai pendidikan karakter ini terkandung dalam beberapa materi, diantaranya:

a. Teks qiraah “البسانترين".

b. Teks hiwar "التعليم في إندونيسيان" "النيا"

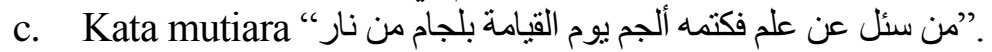

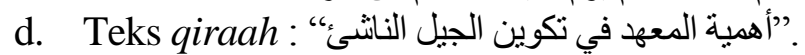

Adapun metode yang digunakan dalam mengintegrasikan nilainilai karakter dalam pembelajaran bahasa Arab di Pusat Pengembangan Bahasa UIN Sunan Kalijaga Yogyakarta diantaranya melalui: (1) penyesuaian nilai karakter dengan materi perkuliahan yang diajarkan, (2) menyisipkan nilai karakter atau mencoba mengambil pelajaran di setiap materi perkuliahan, (3) penyampaian nilai karakter melalui metode pembelajaran yang digunakan, dan (4) penanaman serta penerapan nilai pendidikan karakter dalam kehidupan sehari-hari.

Sedangkan kendala yang dihadapi dosen dalam proses penanaman pendidikan karakter antara lain: (1) sulitnya menyesuaikan nilai pendidikan karakter terhadap materi yang ada. Artinya tidak setiap materi perkuliahan yang diajarkan mengandung muatan nilai karakter, sehingga dosen dalam hal ini harus pandai menghubungkan materi yang ada dengan muatan nilai di dalamnya. (2) sifat dan karakter mahasiswa yang berbeda antara satu dengan lainnya. Sudah merupakan hal yang lazim terjadi di dalam suatu kelompok pembelajaran terdapat keragaman karakter peserta didik, termasuk tingkat pengetahuan antar satu dengan yang lainnya juga kadang berbeda. Dalam hal ini, dosen harus mampu mengelola kelas dengan baik tanpa mengesampingkan sebagian peserta didik, sehingga seluruh kompetensi sebagai seorang pengajar harus benar-benar dimiliki dan mampu diterapkan oleh seorang dosen terlebih lagi pada kompetensi pedagogik.

\section{Penutup}

Pendidikan karakter sudah selayaknya mendapatkan perhatian yang serius dari berbagai elemen masyarakat. Bukan hanya pada aspek definisi dan teori, tapi lebih pada bagaimana pendidikan karakter itu mampu dipahami dan diterapkan dalam kehidupan seharihari. Pendidikan karakter berupaya mengembangkan karakter yang 
mulia (good character) dengan mempraktikkan dan mengajarkan nilai-nilai moral dan pengambilan keputusan yang beradab dalam hubungan dengan sesama manusia maupun dalam hubungannya dengan Tuhannya.

Pembelajaran dapat digunakan sebagai salah satu upaya untuk menanamkan pendidikan karakter. Hal ini seperti yang telah dilakukan oleh Pusat Pengembangan Bahasa UIN Sunan Kalijaga Yogyakarta yang mengajar nilai-nilai karakter kepada mahasiswa diantaranya: religius, jujur, toleransi, disiplin, kerja keras, mandiri, demokrasi, rasa ingin tahu, semangat kebangsaan, menghargai prestasi, komunikatif, gemar membaca, peduli lingkungan, dan tanggung jawab.

Ini merupakan salah satu contoh penerapan pembelajaran nilainilai pendidikan karakter. Dari penelitian ini, semoga nantinya dapat memberikan inspirasi kepada para pengajar dalam mengajarkan materinya kepada peserta didik juga kepada para peneliti agar dapat mengembangkan kajiannya terhadap pendidikan karakter.

\section{Kepustakaan}

Abdul Wahab, Muhbib. 2008. Epistimologi Dan Metodologi Pembelajaran Bahasa Arab. Jakarta: Lembaga Penelitian Universitas Islam Negeri Syarif Hidayatullah.

Azyumardi Azra. 2002. Paradigma Baru Pendidikan Nasional; Rekonstruksi dan Demokratisasi. Jakarta: Kompas.

Barnawi \& M. Arifin. 2013. Strategi dan Kebijakan Pembelajaran Pendidikan Karakter. Yogyakarta: Ar-Ruzz Media.

Kementerian Pendidikan Nasional Dirjen Pendidikan Dasar Direktorat Pembinaan Sekolah Menengah Pertama. 2011. Panduan Pendidikan Karakter di Sekolah Menengah Pertama. Jakarta: Diknas.

Kesuma, Dharma. dkk. 2012. Pendidikan Karakter Kajian Teodan Praktik Di Sekolah, Bandung: PT Remaja Rosdakarya.

M. Echols, John dan Hasan Shadily. 1979. Kamus Inggris Indonesia. Jakarta: Gramedia. 
Ma'mur Asmani, Jamal. 2012. Buku Panduan Internalisasi Pendidikan Karakter di Sekolah. Yogyakarta: Diva Press.

Majid, Abdul dan Dian Andayani. 2013. Pendidikan Karakter Perspektif Islam. Bandung: PT Remaja Rosdakarya.

Mulyasa, E. 2011. Manajemen Pendidikan Karakter. Jakarta: Bumi Aksara.

Munthe, Bermawy. Desain Pembelajaran. Yogyakarta: Pustaka Insan Madani. 2009.

Muslich, Masnur. 2014. Pendidikan Karakter Menjawab Tantangan Krisis Multidimensional. Jakarta: Bumi Aksara.

Mustofa, Syaiful. 2011. Strategi Pembelajaran Bahasa Arab Inovatif. Malang: UIN Maliki Press.

Nata, Abudin. 2005. Filsafat Pendidikan Islam. Jakarta: Gaya Media Patama.

Pambudi, Thoyib Panji. 2014. Pengintegrasian Nilai Karakter Dalam Pembelajaran Bahasa Arab di MTs Negeri Sayegan Tahun Ajaran 2013/2014. Skripsi. Fakultas Ilmu Tarbiyah dan Keguruan UIN Sunan Kalijaga Yogyakarta.

Samani, Muchlas dan Hariyanto. 2013. Konsep Dan Model Pendidikan Karakter. Bandung: PT Remaja Rosdakarya.

Suharso dan Ana Retnoningsih. 2011. Kamus Besar Bahasa Indonesia edisi lux. Semarang: Widya Karya.

Suyadi. 2013. Strategi Pembelajaran Pendiikan Karakter. Bandung: PT Remaja Rosdakarya.

Tim Penyusun Modul Perkuliahan Bahasa Arab. 2013. Al-Jami'ah li Ta'lim al-Lughah al-'Arabiyah. Yogyakarta: Pusat Pengembangan Bahasa UIN Sunan Kalijaga Yogyakarta.

Tim Penyusun. 2008. Kamus Bahasa Indonesia, (Cet. XVI; Jakarta: Pusat Bahasa.

Ulwan, Nasih A. 1992. Tarbiyatul Awlaad fi al-Islaam, Cet.XXI, Jilid I. Jeddah: Daarussalaam.

Undang-Undang Republik Indonesia Nomor 20 Tahun 2003 Tentang Sistem Pendidikan Nasional. 
144 | Agung Setiyawan

Wibowo, Agus. 2012. Pendidikan Karakter, Strategi Membangun Karakter Bangsa Berperadaban. Yogyakarta: Pustaka Pelajar.

Zubaedi. 2013. Desain Pendidikan Karakter. Jakarta: Kencana. 